Neste artigo narra-se parte da história da instituição Pré-Escola Terapêutica Lugar de Vida através do olhar e experiência de um dos profissionais $\mathrm{da}$ equipe. Privilegia-se a história da montagem dos "ateliês de artes".

Levantam-se eixos fundamentais referentes ao estilo de tratamento e escolarização de crianças propostos pela instituição. A partir de um fragmento clínico, ilustra-se o cotidiano do enquadre dos "ateliês de artes" do Lugar de Vida.

\section{A PLACE OF STORIES}

In the article that follows appears the description of part of the institution bistory in the point of view and experience of one of the professionals envolved with the work group. The bistory of the "art atteliers" is put in its foreground. The determining of the essential coordinates referring to the basics of the treatment and the children schooling are proposed by the institution. From a clinical scrap onwards the day by day of the "art atteliers" in the "Pré-Escola Terapêutica Lugar de Vida" is described.

\section{UM LUGAR $\mathrm{DE}$ HISTÓRIAS}

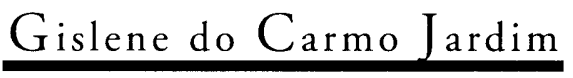

“... todos os dias é um vai e vem, a vida se repete na estação.

Tem gente que chega pra ficar, tem gente que vai pra nunca mais.

Tem gente que vem e quer voltar, tem gente que vai e quer ficar. Tem gente que veio só olbar, tem gente a sorrir e a chorar. $E$ assim, chegar e partir são só dois lados da mesma viagem;

o trem que chega é o mesmo trem da partida.

$A$ bora do encontro é também despedida; a plataforma desta estação é a vida desse meu lugar, é a vida desse meu lugar, é a vida!"

\section{Milton Nascimento e Fernando Brant}

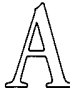

vida deste lugar é mesmo curiosa!

Como diz a canção ${ }^{1}$, “...chegar e partir são só dois lados da mesma viagem; o trem que chega é o mesmo trem da partida..." Gente que chega e gente que vai. Neste lugar espera-se que o trem da vida leve para lugares diferentes dos de origem a 'gente pequena' que por aqui passa; também a vida da 'gente grande' desse lugar tem rumos infinitos. Histórias se entremeiam para

Psicanalista, coordenadora do Ateliê de Música (1992-96), atualmente é supervisora clínica, coordenadora dos assuntos acadêmicos e dos ateliês de Artes e de Ofícios da Pré-Escola Terapêutica Lugar de Vida. Mestre em Psicologia Escolar pelo Instituto de Psicologia da USP. 
que surjam novos sentidos. O Lugar de Vida encanta, canta e faz dançar.

Há controvérsias sobre a história de sua origem. Cada um que fala dela a coloca em um marco, exatamente naquele ponto em que foi capturado por uma rede de sentido, seja do lado de quem vai tratar, seja do lado de quem será tratado; não importa, uma mesma rede tecida enlaça os dois lados dessa história, para que outras histórias possam ser contadas, pois no Lugar de Vida há a suposição de que aí se pode tratar de crianças que estão fora da rede viva da cultura.

Imagino que as cinco psicanalistas ${ }^{2}$ que em 1988 se encontravam diante do dilema de tratar crianças de um modo novo - crianças, à época, denominadas "gravemente comprometidas" - não pensavam que o que iniciavam seria semente para muitos frutos. Hoje, a estrutura do Lugar de Vida comporta profissionais das áreas da saúde e da educação de crianças. São muitas crianças, muitos pais, muitos profissionais envolvidos, muitos alunos, muitas histórias, enfim.

Em 1991, quando chegou à Universidade de São Paulo trazido por mérito de Cristina Kupfer, o Lugar de Vida apresentava apenas duas modalidades de atendimento, o "grupo terapêutico" e o "grupo educacional", instâncias que já nos permitiam falar do valor da 'alternância' entre um grupo e outro na direção do tratamento das crianças que recebíamos. Em seguida, o "grupo de escuta dos pais" rapidamente foi proposto para circundar melhor o campo de tratamento daquelas crianças. A orientação psicanalítica lacaniana nos iluminou no que diz respeito ao não recuo diante das psicoses, bem como à necessidade de mudanças no manejo transferencial para a condução de um tratamento. Entre os profissionais da equipe - desde o início permeada pela presença de entusiasmados aprendizes da arte de psicanalizar -, empreendemos estudos acerca do diagnóstico diferencial, do tratamento, da escolarização e da estrutura montada para abarcar as crianças excluídas de lugares sociais. Tarefa por vezes árdua, por vezes vital à quem se implicou, em nome do próprio desejo, nesta pequena - e grandiosa - instituição.

Foi pelo desejo de alguns que novas instâncias foram levantadas no Lugar de Vida. Neste contexto, em 1991, surgem com muita delicadeza o "ateliê de música" e o "ateliê de contar histórias", instâncias gêmeas da origem do espaço das artes nesta instituição. Eu diria não somente espaços privilegiados das linguagens artísticas, mas principalmente, espaços potencializados da garantia de que no Lugar de Vida pode-se, sim, falar em infância feliz. Muito timidamente e movidas pelo desejo próprio iniciamos a construção de um campo da infância dos sonhos, em que se brinca, se cria, se diverte, se aprende e, principalmente, compartilha-se com o outro. Para as crianças que chegam ao Lugar de Vida há um impedimento estrutural de que a infância seja vivida desta maneira; 
por isso a concepção de uma estrutura que acolha, que dê bordas, que lance redes para um possivel usufruto do infantil ainda na infância.

Seguidos aos ateliês de "música" e de "contar histórias" foram gerados e concebidos os ateliês de "jogos dramáticos" e do "cotidiano". Quantas discussões, reuniões, assessorias específicas e supervisões para dar conta da 'especialidade' do desejo - se é que se pode qualificar desta forma um desejo - daqueles que com este trabalho se envolviam. Lembro-me de uma jornada em que cada dupla de coordenadores apresentou seus projetos, tanto aqueles que puderam produzir efeitos nas crianças como também projetos que foram abortados por elas. Nos relatos, em cada um deles, ouvia-se o desejo de quem o pronunciava e cada ateliê abordado era como se uma porta da instituição se abrisse em nome do Belo; em cada porta aberta vislumbrávamos um baú de riquezas oferecidas às crianças: histórias infantis, brincadeiras, cores, músicas, doces e escovas de dentes, é claro! Quanta vida, quanta magia, quanta ilusão, quanto testemunho de que uma criança pode produzir, produzindo-se sujeito. É claro que falava-se também do impossivel, que correspondia exatamente ao furor curandis. Com a ampliação das alternâncias testemunhávamos a possibilidade da alienação e da separação, conceitos psicanalíticos fundamentais na clínica com crianças. E muita escuta, muita relativização das açòes e, principalmente, muita paciência na feitura do sujeito fora do seu lugar natural, ou seja, para além da estrutura familiar, transmissora de significantes fundamentais ao sujeito. Todo o contexto do tratamento no Lugar de Vida pressupõe este outro tempo da constituição subjetiva. Vale lembrar que as diferentes instâncias unem-se numa única direção do tratamento, digamos, em um único estilo de tratar, não tendo valor absoluto as pequenas unidades da instituição.

Ser diferente e fazer parte de um todo, árduo paradoxo para a realização de um trabalho com crianças. Como transmitir o Um pela falta intrínseca ao todo? Questão absolutamente psicanalítica, presente em cada uma das instâncias do Lugar de Vida e exaustivamente discutida em reuniões da equipe a partir de várias perspectivas. A reunião da equipe é considerada, por isso, a instância maior da tecedura da rede de histórias que se entrelaçam no Lugar de Vi$d a$ : histórias das crianças, dos seus pais e dos profissionais. Este espaço de discussão é, por muitas vezes, o campo fértil para que uma outra história seja imaginada e antecipada para cada uma das crianças em tratamento na instituição. Falamos, escutamos, discutimos, oposicionamo-nos, duvidamos, questionamos, silenciamos: estas são ações que convergem no eixo norteador das intervenções no Lugar de Vida.

Na esteira dos ajustes das melhores propostas de ofertas de espaços de linguagem às vicissitudes das crianças do Lugar de Vida, instituímos, a partir de 1994, os horários dos "passeios", da "recreação" e das "festas" (aniversários e datas comemorativas). Se durante alguns anos trabalhamos com propostas de linguagens das artes de modo bem circundado, iniciamos, em 1997, uma mudança no enquadre dos ateliês específicos e, hoje, oferecemos uma proposta de "ateliês de artes", nos quais são desenvolvidos projetos de duração variada, em que se privilegiam as diferentes linguagens das artes, enfatizando ora a música, ora as artes plásticas, ora o jogo de representação ou outra linguagem. Os projetos são elaborados a partir das possibilidades das crianças do grupo e do foco de interesse de uma ou mais crianças, foco a partir do qual uma 
cadeia significante poderá ser estendida, dizendo respeito à história daquele grupo.

O tempo de produção e execução de um projeto nos "ateliês de artes" nem sempre ocorre de modo circular contínuo. Em muitos momentos nenhum projeto encampa: crianças em crise, grupo 'enlouquecido', falta de idéias dos coordenadores. É exatamente este o terreno fértil à sementinha para um novo projeto, cabendo aos coordenadores rastrear com uma lupa, o que de uma estereotipia, da agitação motora ou de uma fala ecolálica pode transformarse em uma proposta de atividade que dirá respeito, esperamos, a cada um do grupo. Nestes momentos, colocamo-nos como 'cães farejadores' de significantes de uma história da qual somos testemunhas. Este contexto é sempre propício à angústia, mas também sabemos, pela experiência, que é dos momentos de angústia que uma nova configuração ao desejo poderá ser dada. O que nos resta, então, é trabalhar analiticamente, ou seja, escutando e intervindo no momento possivel de uma intervenção. Não me parece redundância o que digo, pois a escuta analítica nos ensina que um ato clínico nem sempre tem efeito de um ato analítico; sabemos que o terreno da intervenção analítica em instituição poderá ou não encaminhar uma criança para uma análise de fato. Aliás, o encaminhamento da criança para uma análise é um dos objetivos do Lugar de Vida, além, é claro, da sua inclusão escolar.

Mas voltemos aos momentos de silêncio em que, no enquadre dos ateliês, uma intervenção pela linguagem das artes produz um efeito-sujeito nas crianças. Recordo-me de uma criança, não mais em atendimento no Lugar de Vida, que era nomeada pelos profissionais através de significantes como "fada", "borboleta", "princesinha", tamanha le- veza e inconsistência na relação com o outro. Ainda no enquadre do "ateliê de música", pensávamos em como seduzila para esta arte, já que a música está na cultura para deleite de todos que dela faz parte. Oferecemos uma música, outra, instrumentos, alguns sons, até que, após oferecermos um pedaço de papel higiênico para outra criança que estava com a 'meleca de nariz à mostra', aquela menininha frágil, de mãos leves e viajantes e com olhar milimetricamente calculado para escapar do campo do olhar do Outro, interessa-se pelo papel e sai pela sala desenrolando aquele rolo de papel higiênico. Surpreendida com tal ação vinda desta criança tão assustada com a possibilidade de relacionar-se com um outro, tomo outro rolo de papel higiênico e saio pela sala dançando a música e criando uma coreografia provavelmente uma coreografia ridícula vista pelos olhos de bailarinos profissionais - que consistia em me envolver com o papel higiênico e soltá-lo a cada vez que o refrão da música era ouvido. Em outros momentos da música, inventava um movimento que pudesse abarcar aquela menininha que agora não mais calculava seus olhos para não olhar-me. Eu sorria, e ela, timidamente, sorria para mim e imediatamente recolhia seu sorriso. Até que percebi: ela tinha um olhar diferente, um olhar de espera da minha evolução durante o refrão da música. Eu estava ali, ela também; eu ouvia a música e dançava conforme o ritmo e ela também, só que agora não somente no seu ritmo, estereotipado, mas no ritmo que a música provocava em mim e que provocava nela, ao menos, uma mudança de olhar. Este era o contexto: uma das salas de atendimento do Lugar de Vida, uma música oferecida no enquadre do "ateliê de música" (um dos espaços da instituição reconhecidos como espaço de tratamento), a dupla coordenação 
(que possibilitou que eu empreendesse uma ação clínica com valor de intervenção para uma das crianças) e a intervenção dirigida para as outras crianças do grupo (ou seja, a oferta de pedaços de papel higiênico) que também testemunhavam aquele momento de criaçào. Estava tudo posto, sem que no momento vivido tivéssemos a certeza de que poderíamos, naquelas condições, tirar aquela criança do 'mundo dela' e de trazê-la para o 'mundo da cultura'. O que terá sido esta situação senão uma forma de laço social? Não será esta uma das possíveis maneiras de oferecer $O$ discurso social para uma criança que, de modo particular, recusa-se a incluirse nele? É possivel ofertar um Outro não ameaçador através da intervenção analítica em instituição? Penso que este pequeno fragmento ilustra as inúmeras situações em que tentamos, delicadamente, oferecer o campo da linguagem para crianças que estão fora do discurso. O tratamento e a escolarização oferecidos no Lugar de Vida ocorrem através da oferta de significantes disponíveis na cultura em enquadres diferenciados; a recuperação dos momentos de relação de cada uma das crianças nas diferentes atividades e, como conseqüência disto, a construção de um saber sobre elas - saber desdobrado dos significantes da criança na instituição -, possibilitam que cada história familiar seja tocada de modo a produzir mudança na posição gozosa da criança em relação ao desejo dos pais e destes em relação à elas.

Para finalizar, vale lembrar que o Lugar de Vida é lugar de passagem, para as crianças, para os adultos. Nesta caracteristica está embutida a idéia de instituição não-toda, faltante, que tem como estilo o empreendimento da busca a cada novo impasse. Instituição que, por isso, tenta abordar o que por vezes parece inabordável, a conter o incontí- vel, a atingir o inatingível. Estamos no espectro da loucura e, por isso, no limite dos desejos.

A vida deste lugar é mesmo curiosa!

Parafraseando o poeta, “...é a vida desse meu lugar, é a vida!"

Lugar de Vida: lugar de histórias de vida!

\section{NOTAS}

1 Refiro-me à cançào "Encontros e Despedidas" de Milton Nascimento e Fernando Brant.

2 Refiro-me às psicanalistas Maria Cristina Machado Kupfer, Lina Galletti Martins de Oliveira, Marize Lucila Guglielmetti, Lia Grillo e Vivian Lembo que, ainda em consultório particular, iniciaram a proposta de atendimento em grupo de crianças gravemente comprometidas, proposta que deu origem à montagem do dispositivo de tratamento e escolarização PréEscola Terapêutica Lugar de Vida", em funcionamento, desde 1991, junto ao Instituto de Psicologia da Universidade de São Paulo. 